\title{
Photochromism in spiropyran impregnated fluorinated mesoporous organosilicate films
}

\author{
Jae Young Bae, Ji-In Jung, and Byeong-Soo Bae ${ }^{\text {a) }}$ \\ Laboratory of Optical Materials and Coating (LOMC), Department of Materials Science and \\ Engineering, Korea Advanced Institute of Science and Technology (KAIST), \\ Daejeon 305-701, Republic of Korea
}

(Received 4 December 2003; accepted 27 May 2004)

\begin{abstract}
Fluorinated mesoporous organosilicate films were synthesized by sol-gel spincoating on a quartz substrate using (heptadecafluorodecyl)trimethoxysilane, tetramethylorthosilicate, and $n$-cetyltrimethylammonium chloride as the fluoro-precursor, silica source, and supramolecular template, respectively. The photochromism efficiency of photochromic dyes (spiropyran) increases in the order non-porous $<$ hexagonal mesoporous $<$ fluorinated mesoporous organosilicate films. The relatively high efficiency of the photochromism of spiropyran in fluorinated mesoporous organosilicate films suggests that such films are promising materials for applications as optical shutters and light modulators.
\end{abstract}

\section{INTRODUCTION}

Scientists at Mobil Corporation (Poulsboro, NJ) synthesized silica-based mesoporous molecular sieves with hexagonal, cubic, and lamellar structures called M41S materials in $1992 .{ }^{1}$ These materials have high surface areas, ordered pore mesostructures, and uniform pore sizes. Mesoporous silica thin films show promise in applications such as membrane separations, chemical sensors, optical devices, and electronic devices such as low- $k$ dielectric films. ${ }^{2-4}$ Mesoporous thin films can be formed by spin coating or dip coating in what is called evaporation induced self-assembly (EISA) ${ }^{5-7}$ By changing the ratio of surfactant to silica precursor solutions, the silica films were found to acquire lamellar, hexagonal, or cubic mesostructures. ${ }^{8,9}$

Early attempts to incorporate guest species in the mesoporous sorbent MCM-41 resulted in low guest loadings, probably due to the absence of specific interactions between the host mesoporous materials and guest molecules. The use of organically functionalized mesoporous materials may alleviate this problem, and the synthesis of inorganic-organic hybrid mesoporous silica has recently been reported. ${ }^{10}$ Chemical functionalization of the inorganic framework of porous materials, for example through the covalent coupling of an organic moiety, is a promising approach to specific pore surface properties

\footnotetext{
a) Address all correspondence to this author.

e-mail: bsbae@kaist.ac.kr

DOI: $10.1557 / J M R .2004 .0315$
}

such as hydrophobicity, polarity, and catalytic, optical, and electronic activity. ${ }^{11,12}$

In the present study, optically transparent and crackfree fluorinated mesoporous organosilicate films have been synthesized by sol-gel spin-coating on a quartz substrate using (heptadecafluorodecyl)trimethoxysilane, tetramethylorthosilicate, and $n$-cetyltrimethylammonium chloride as the fluoro-precursor, silica source, and supramolecular template, respectively. Photochromic materials, which change their color reversibly in response to light, can be applied to optical waveguides, shutters, light modulators, and optical storage media when these dyes are incorporated into appropriate matrices. ${ }^{13,14}$ For optical applications, a high photochromism efficiency is required. ${ }^{15}$ For this purpose, a wide range of chemically various matrices, e.g., as non-porous, hexagonal mesoporous, and fluorinated mesoporous organosilicate films have been investigated for photochromic dyes and their efficiency compared.

\section{EXPERIMENTAL}

\section{A. Preparation of mesoporous silica films}

The mesoporous silica films were synthesized according to the procedure described in the literature. ${ }^{8,9}$ The mesoporous silica films were prepared as follows; tetramethylorthosilicate (TMOS; Aldrich, Milwaukee, WI, $98 \%$ ) was hydrolyzed under acidic conditions ( $\mathrm{HCl}$, J.T. Baker, Phillipsburg, NJ, 36.5-38\%). Methanol $\left(\mathrm{CH}_{3} \mathrm{OH}\right.$; Merck, Whitehouse Station, NJ, 99.8\%) was then added into the hydrolyzed TMOS at room temperature. Finally, cetyltrimethylammonium chloride $(\mathrm{CTACl}$; Aldrich, 
$25 \%$ ) was added to achieve final reactant mole ratios of 1 TMOS:17-18 H2O:0.09-0.11 HCl:6-20 $\mathrm{CH}_{3} \mathrm{OH}: 0.15-$ $0.25 \mathrm{CTACl}$. The solution was allowed to react for another $24 \mathrm{~h}$ at room temperature to achieve oligomerization. The prepared solution was then deposited on a quartz substrate $(4 \mathrm{~cm} \times 4 \mathrm{~cm} \times 0.8 \mathrm{~mm})$ using the spin coating method. The silica-surfactant composite thin films were pre-dried at 60,130 , and $200{ }^{\circ} \mathrm{C}$ for $1 \mathrm{~h}$ at each stage using the increasing heat procedure to remove the solvent, water, and organic template. The pre-dried films were then calcined in flowing air at $450{ }^{\circ} \mathrm{C}$ for 12 $\mathrm{h}$ at the rate of $1{ }^{\circ} \mathrm{C} / \mathrm{min}$ to remove the organic template thoroughly. The nonporous silica films were also prepared without surfactants following the literature procedure $^{8,9}$ as like mesoporous silica films.

\section{B. Preparation of fluorinated mesoporous organosilicate films}

Mesoporous fluorinated organosilicate films were synthesized at room temperature from TMOS and (heptadecafluorodecyl)trimethoxysilane (17-FDTMS; Toshiba, Kawasaki, Japan) in the presence of a surfactant, $\mathrm{CTACl}$. The following chemicals were used without further purification; 17-FDTMS was hydrolyzed in distilled water containing $0.01 \mathrm{~N}$ hydrochloric acid as a catalyst for the sol-gel reaction. 17-FDTMS was reacted with dilute $\mathrm{HCl}$ to avoid the unwanted precipitation of hydrophobic organoalkoxysilane. TMOS was added to the hydrolyzed 17-FDTMS in a molar ratio of 9:1. The mixed solution was hydrolyzed under acidic conditions and then methanol was added. Finally, CTACl was added to achieve final reactant mole ratios of 0.9 TMOS:0.1 17FDTMS: 8-16 $\mathrm{H}_{2} \mathrm{O}: 0.0005-0.0006 \mathrm{HCl}: 18-30 \mathrm{CH}_{3} \mathrm{OH}$ : $0.0038-0.25 \mathrm{CTACl}$. The solution was allowed to react for another $24 \mathrm{~h}$ at room temperature to oligomerize. The solution was dropped onto a spinning on a quartz substrate at a spinning rate of $2000 \mathrm{rpm}$ and all films were prepared by single coating. Thermogravimetric analysis of the as-synthesized fluorinated samples showed weight losses near 60,260 , and $510{ }^{\circ} \mathrm{C}$. The peak losses indicate the desorption of solvent and the decomposition of $\mathrm{CTACl}$ and perfluoroalkyl chains. For the purpose of complete decompositions of the surfactant and prevention of the decomposition of the perfluoroalkyl chains, the calcination temperature was set at around $350{ }^{\circ} \mathrm{C}$.
This temperature was obtained from TGA results. The films were calcined in flowing air at $350{ }^{\circ} \mathrm{C}$ for $12 \mathrm{~h}$ at rate of $1{ }^{\circ} \mathrm{C} / \mathrm{min}$ to remove the organic template.

\section{Characterization of mesoporous films}

The transparent films were characterized by various methods as follows. X-ray diffraction (XRD) patterns of all mesoporous films were obtained on a Rigaku (Tokyo, Japan) D/MAX-RC diffractometer with $\mathrm{Cu} \mathrm{K}_{\alpha}$ radiation $(40 \mathrm{kV}, 80 \mathrm{~mA})$ at $0.01^{\circ}$ step width and $1 \mathrm{~s}$ step time over the range $1.2^{\circ}<2 \theta<10^{\circ}$. Thermogravimetric analysis (TGA) was performed on a TGA 2050 analyzer from TA Instruments (New Castle, DE) with a heating rate of $5{ }^{\circ} \mathrm{C}$ $\min ^{-1}$ in nitrogen flow. Transmission electron micrographs of the calcined films were recorded on a JEOL (Peabody, MA) JEM-2000EX electron microscope operating at $200 \mathrm{kV}$. Cross-sectional film samples on Si wafers were prepared by placing films directly onto an epoxy resin substrate. Cross-sectional slices were cut using ultramicrotome and deposited on a copper grid. Scanning electron microscopy (SEM) images were recorded on a Philips (Eindhoven, Netherlands) 535M apparatus operating at $20 \mathrm{kV}$. Infrared spectroscopy was measured by using a Bruker EQUINOX55 FTIR (Billerica, MA). The ultraviolet-visible (UV-vis) absorption spectra were recorded using a Shimadzu (Kyoto, Japan) UV-3010PC spectrophotometer. The relative efficiency of the photochromism of spiropyran (SP) in calcined films before and after photoirradiation at room temperature for different times was described by using UV-vis absorption spectra.

A photochromic dye, namely 1',3'-dihydro-1'hydroxyethyl-3', $3^{\prime}$-trimethyl-6-nitrospiro[2H-1benzopyran-2,2'-2(H)-indole], a spiropyran (SP) was used as received from Dr. J.H. Kim (Kyung Hee University, Suwon, Republic of Korea). The SP dye was incorporated into the silica films by impregnation. The silica films were placed into $10 \mathrm{ml} 1.5 \times 10^{-3} \mathrm{M}$ SP dye in ethanol for overnight in the dark. Ethanol was removed by flowing nitrogen gas over the sample for $30 \mathrm{~min}$. This structure is given in Fig. 1 together with one of the several reaction products upon illumination for the SP dye. ${ }^{16}$ Reversible photocoloration is attributed to equilibrium between the spiropyran (closed, colorless) form and a merocyanine (open, colored) form as shown in Fig. 1.
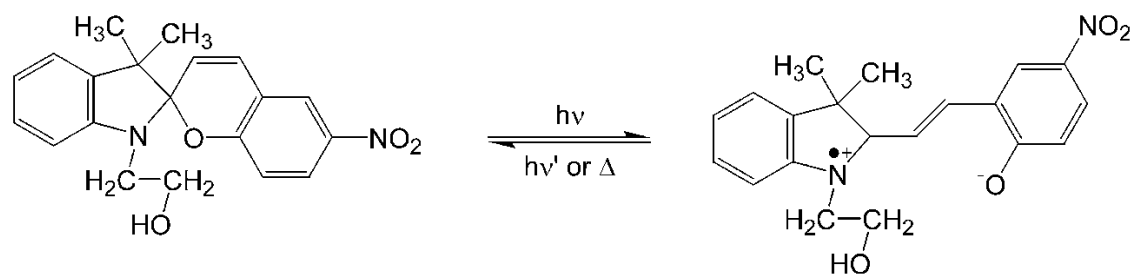

FIG. 1. Structure of the photochromic dye and one of its corresponding merocyanine form. 


\section{RESULTS AND DISCUSSION}

\section{A. Characteristics of mesoporous films}

XRD patterns of as-synthesized and calcined hexagonal mesoporous silica films in Figs. 2(a) and 2(b) indicate that a mesoporous structure is formed on the quartz substrate. XRD patterns show a prominent peak at $2 \theta=2.0^{\circ}$ to $4.0^{\circ}$ and some broad peaks at $2 \theta=4.0^{\circ}$ to $7.0^{\circ}$ characteristic of hexagonal structure. The unit cell parameter $\left(a_{\mathrm{o}}\right)^{17}$ for a hexagonal structure is calculated from $d(100)$ according to $\left(a_{\mathrm{o}}\right)=2 d(100) / 3^{1 / 2}$ where $d(100)$ is obtained from the $2 \theta$ value of the first peak in the XRD pattern from $d(100)=\lambda / 2 \sin \theta$ where $\lambda=0.15417 \mathrm{~nm}$ for the $\mathrm{Cu} \mathrm{K} \mathrm{K}_{\alpha}$ line. The unit cell parameter $a_{\mathrm{o}}$ is equal to the internal pore diameter plus one pore wall thickness. As-synthesized mesoporous silica film as shown in Fig. 2(a) shows a $d(100)$ value of $3.49 \mathrm{~nm}$ and unit cell parameter of $4.03 \mathrm{~nm}$. According to the XRD patterns, the mesoporous structure is retained even after decomposition of CTACl by calcination at $450{ }^{\circ} \mathrm{C}$ in flowing air for $12 \mathrm{~h}$. The XRD of calcined mesoporous silica film as shown in Fig. 2(b) is similar to that prior to calcination

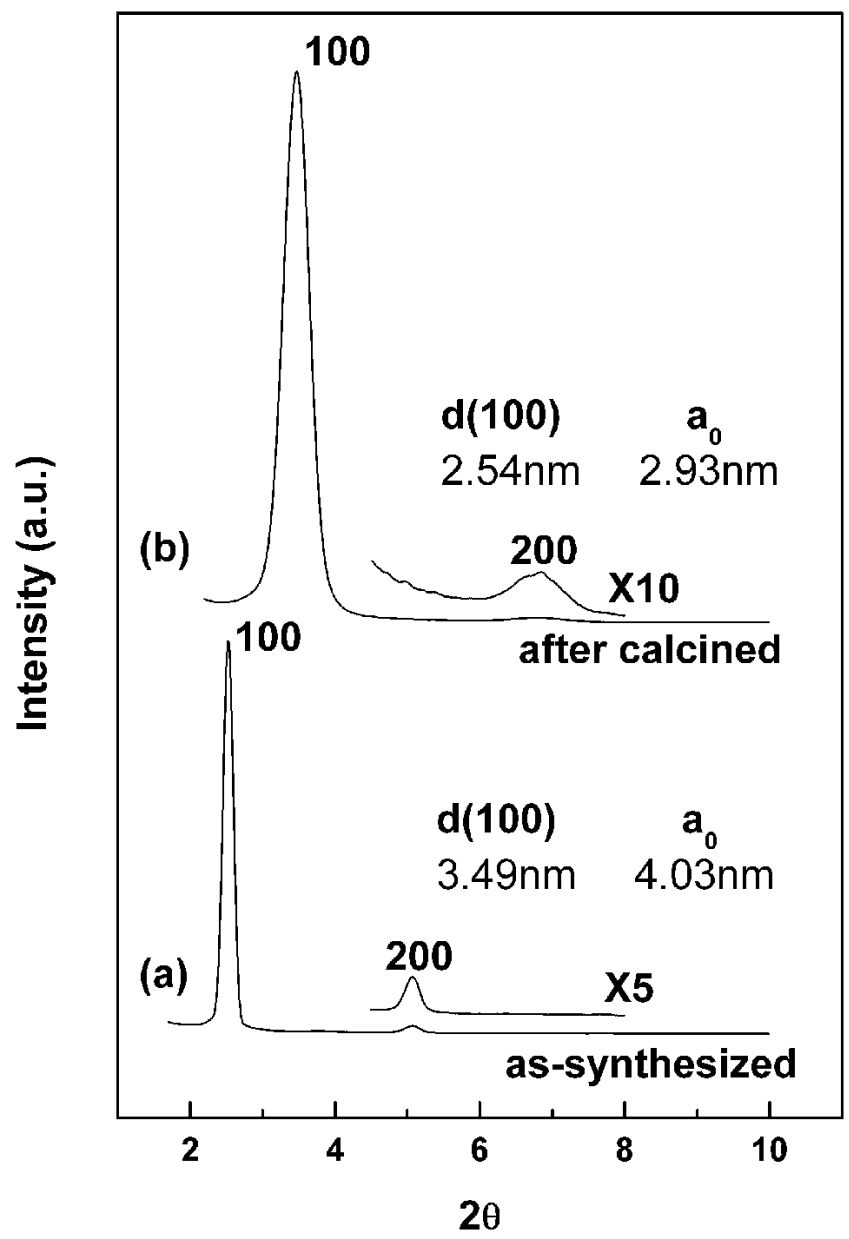

FIG. 2. XRD patterns of (a) as-synthesized and (b) calcined hexagonal mesoporous silica films. except for a substantial decrease in $d(100)$ to $2.54 \mathrm{~nm}$ with a unit cell parameter of $2.93 \mathrm{~nm}$. The broadening of the $d(100)$ peak on calcination suggests less structural ordering in the film after calcination.

XRD patterns of as-synthesized and calcined fluorinated mesoporous organosilicate films in Figs. 3(a) and 3(b) indicate that fluorinated mesoporous structure is formed on a quartz substrate. As-synthesized fluorinated mesoporous organosilicate films as shown in Fig. 3(a) have a $d(100)$ value of $4.21 \mathrm{~nm}$ and unit cell parameter of $4.86 \mathrm{~nm}$. TGA (not shown) of as-synthesized fluorinated mesoporous organosilicate films shows a weight loss about $65 \%$ on heating to $700{ }^{\circ} \mathrm{C}$. Three endothermic losses near $60{ }^{\circ} \mathrm{C}$ ( $3 \%$ weight loss), $260{ }^{\circ} \mathrm{C}$ (31\% weight loss) and $510{ }^{\circ} \mathrm{C}(31 \%$ weight loss) are observed. The weight loss at $60{ }^{\circ} \mathrm{C}$ is assigned to water desorption. The weight losses at 260 and $510{ }^{\circ} \mathrm{C}$ are assigned to decomposition of $\mathrm{CTACl}$ and perfluoroalkyl chains. According to the XRD patterns, the fluorinated mesoporous structure is retained even after decomposition of CTACl by calcination at $350{ }^{\circ} \mathrm{C}$ in flowing air for $12 \mathrm{~h}$. The XRD of calcined fluorinated mesoporous organosilicate films

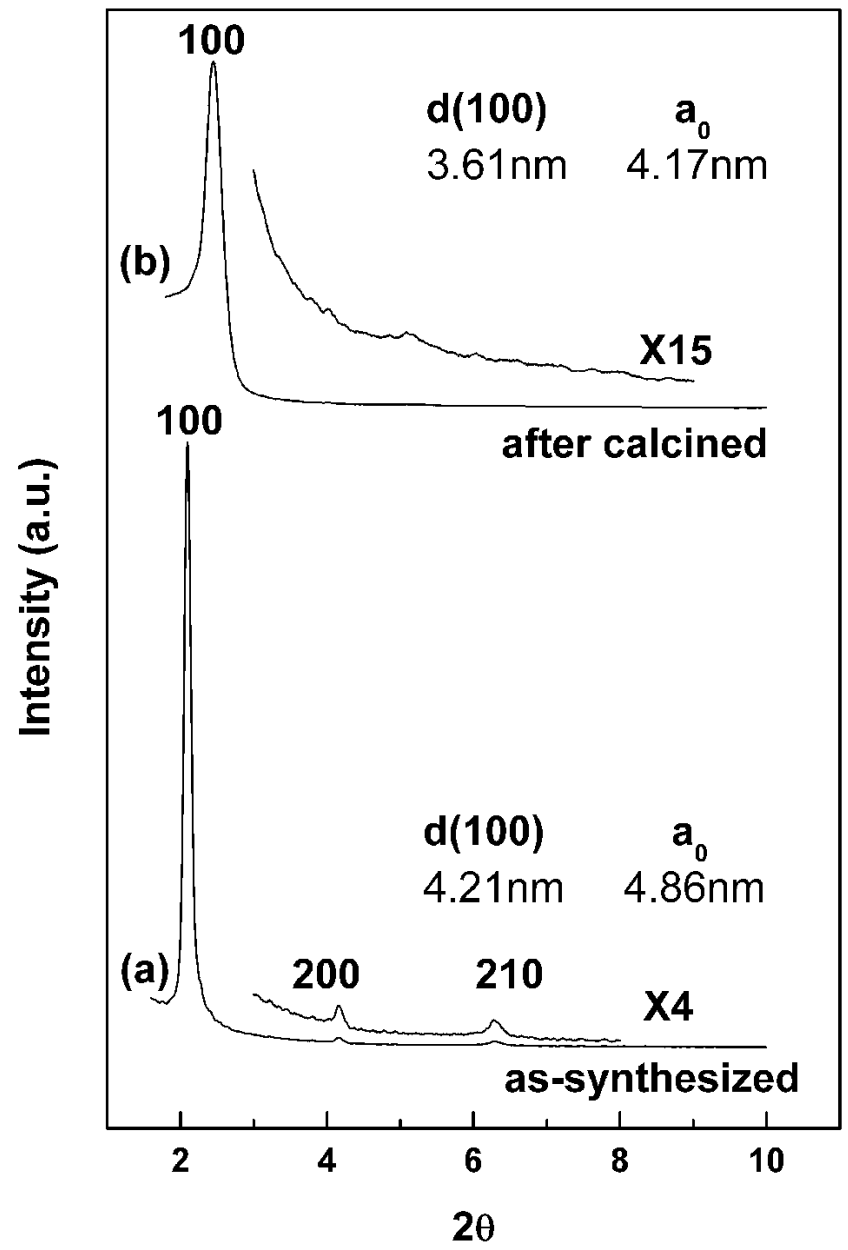

FIG. 3. XRD patterns of (a) as-synthesized and (b) calcined hexagonal fluorinated mesoporous organosilicate films. 
as shown in Fig. 3(b) is similar to that prior to calcination except for a substantial decrease in $d(100)$ to $3.61 \mathrm{~nm}$ with a unit cell parameter of $4.17 \mathrm{~nm}$. However, the final calcination temperature $\left(350{ }^{\circ} \mathrm{C}\right)$ of fluorinated mesoporous organosilicate films is different with that $\left(450^{\circ} \mathrm{C}\right)$ of pure mesoporous silica films. Therefore, XRD patterns of fluorinated mesoporous organosilicate films with perfluoroalkyl chain after calcinations at low temperature are expected to have weak peaks as shown in Fig. 3.

The ordered structures of the calcined fluorinated silicate [Fig. 4(a)] and pure hexagonal mesoporous silica [Fig. 4(b)] films were further confirmed by crosssectional transmission electron microscope (TEM) images. However, well-resolved TEM images of fluorinated mesoporous organosilicate films were not obtained. The thicknesses of the calcined fluorinated silicate and pure hexagonal mesoporous silica films are about $400-410 \mathrm{~nm}$ as measured by cross-sectional SEM.

Figure 5 shows the Fourier transform infrared (FTIR) spectra of the as-synthesized fluorinated mesoporous organosilicate films and samples heated at 350 and $450{ }^{\circ} \mathrm{C}$. The band appearing at around $1072 \mathrm{~cm}^{-1}(\alpha)$ is associated with $\mathrm{Si}-\mathrm{O}-\mathrm{Si}$ asymmetric bond stretching. ${ }^{18}$ The bands at 1146 and $1206 \mathrm{~cm}^{-1}$ are assigned to $\mathrm{C}-\mathrm{H}$ bending and $\mathrm{C}-\mathrm{F}$ stretching modes in the perfluoroalkyl chains $(\beta$ and $\gamma) .{ }^{19}$ Perfluoroalkyl groups appeared to be degradated in the spectra after calcination at $450{ }^{\circ} \mathrm{C}$. Finally, the films calcined at $350{ }^{\circ} \mathrm{C}$ showed perfluoroalkyl groups covalently bonded to $\mathrm{Si}$ atoms thus resulting in the formation of fluorinated mesoporous organosilicate films.

\section{B. Photochromism of fluorinated mesoporous organosilicate films}

In general, the mesostructured materials ${ }^{15}$ with doped dye are mesophase films without calcination process. However, the used films in this study are inorganicorganic hybrid mesoporous materials with thermal and structural stability through calcinations process. Figure 6 shows the UV-vis absorption spectra of SP in calcined fluorinated mesoporous organosilicate films before and after photoirradiation at room temperature for different times. The calcined fluorinated mesoporous organosilicate films with incorporated SP dye were irradiated using a 500 W NUV source mercury lamp (Oriel 97435, Stratford, CT) at $365 \mathrm{~nm}$. After illumination of different UV irradiation times at room temperature, the samples turn violet and the absorption spectrum in the visible range is similar to the absorption spectrum of SP in ethanol. ${ }^{22}$
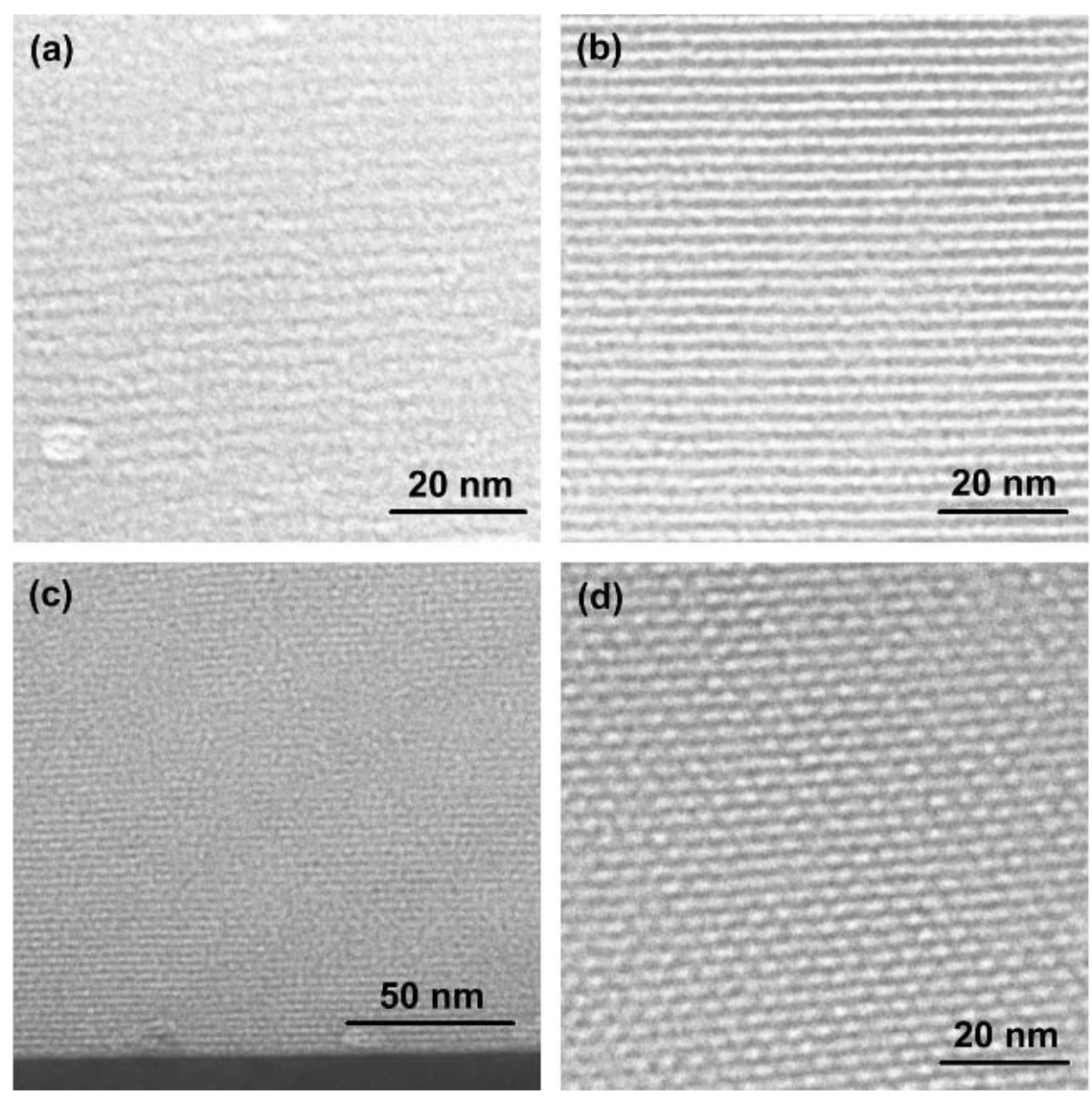

FIG. 4. Cross-sectional TEM images of calcined (a) fluorinated mesoporous organosilicate and (b) pure hexagonal mesoporous silica films. Cross-sectional TEM images including substrate of perpendicular (c), and through (d) the pores of pure hexagonal mesoporous silica films. 


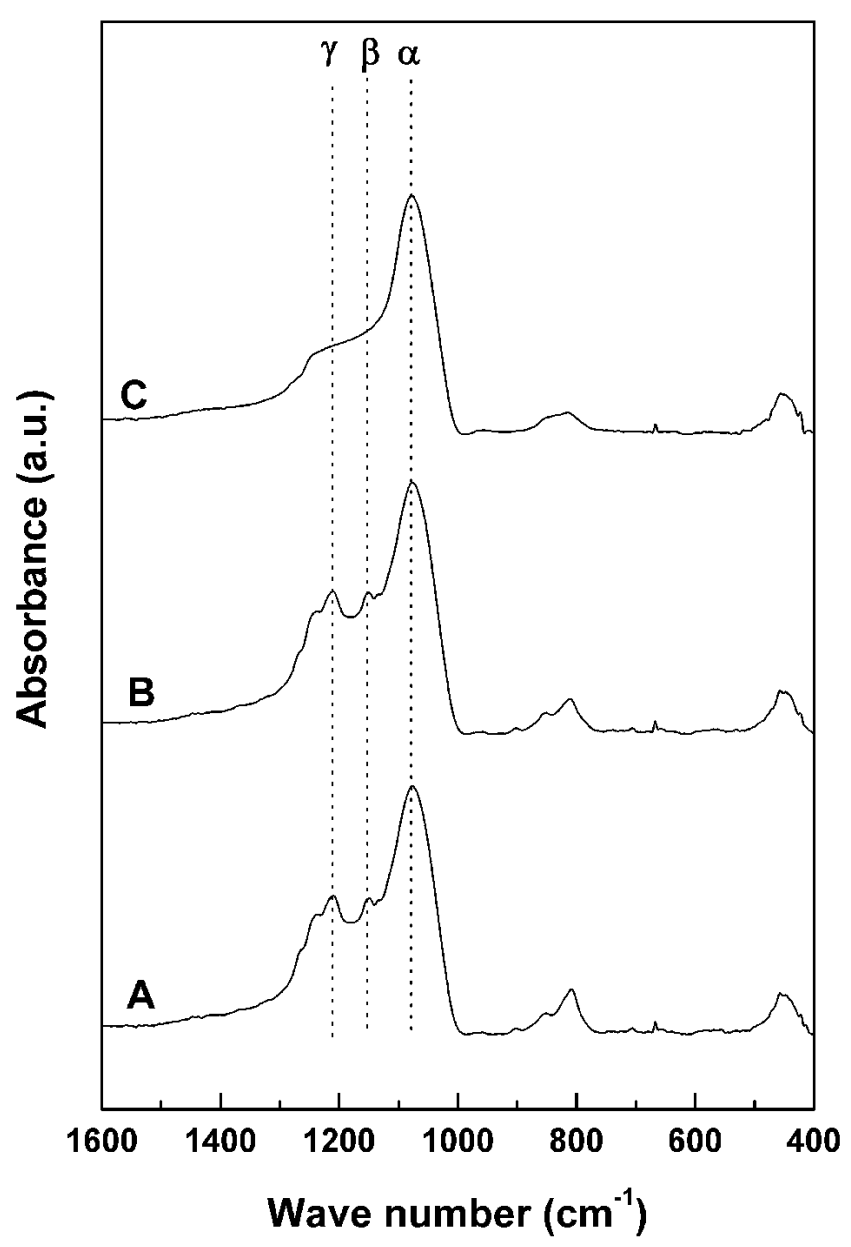

FIG. 5. FTIR absorption spectra of fluorinated mesoporous organosilicate films. The y-axis shows the relative intensities of the absorption coefficient. Spectra A-C correspond to the samples after coating, calcination at $350{ }^{\circ} \mathrm{C}$, and calcination at $450{ }^{\circ} \mathrm{C}$, respectively.

From Fig. 6 it is seen that the UV-vis signals increase rapidly during the first $5 \mathrm{~min}$ and then almost reach a plateau. The calcined fluorinated mesoporous organosilicate films with incorporated SP dye show a single broad absorption in the visible range with a maximum at around $553 \mathrm{~nm}$. The band maximum position for the transient spectra was found to be similar to that of SP in ethanol, ${ }^{20}$ which varies with concentration between 550 $\mathrm{nm}\left(4 \times 10^{-5} \mathrm{M}\right)$ and $532 \mathrm{~nm}\left(10^{-2} \mathrm{M}\right)$. The impregnation of SP dye into the fluorinated mesoporous organosilicate and hexagonal mesoporous silica films was confirmed by us previously ${ }^{9,21,22}$ from nitrogen adsorption-desorption isotherms. Nitrogen adsorption-desorption isotherms were actually measured by using powder samples. In analogy with previous results, ${ }^{21}$ we conclude that the SP dye is similarly incorporated into the pores of the fluorinated mesoporous organosilicate and hexagonal mesoporous silica films. Before UV irradiation, the SP dye incorporated in these films shows shorter wavelength region $(520 \mathrm{~nm})$. The results arise from the surface

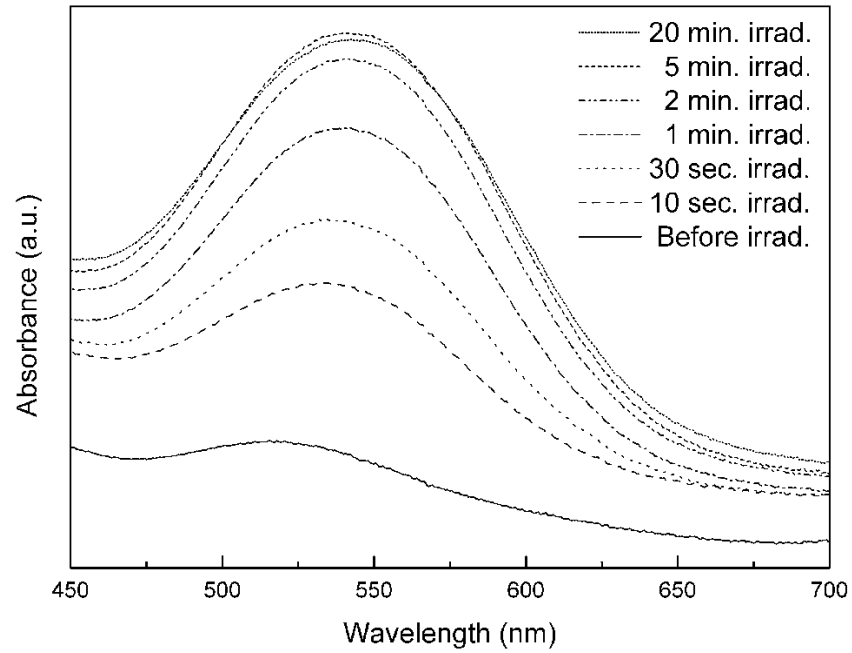

FIG. 6. Absorption spectra of SP in fluorinated mesoporous organosilicate films at room temperature with different photoirradiation times at $365 \mathrm{~nm}$.

aggregation of the SP dye. As UV irradiation time increases, the SP dye incorporated in these films show gradually shifting longer wavelength. These results arise from mesoporosity reducing the aggregation of the SP dye and hydrophobic interaction between SP dye and fluorine.

Table I shows unit cell parameter and dynamic behavior $(\Delta A)$ of photochromism of SP dye-containing nonporous, hexagonal mesoporous, and fluorinated mesoporous materials. The nonporous silica films were prepared following the literature procedure ${ }^{9,22}$ without any supramolecular template. The fluorinated mesoporous organosilicate, hexagonal mesoporous silica, and nonporous silica films with incorporated SP dye show broad absorption in the visible range with a maximum at around 553, 550, and $515 \mathrm{~nm}$, respectively. $\Delta A$ does mean the value obtained by subtracting the absorbance before UV irradiation from that at the photostationary state (5 min) after UV irradiation. The kinetic equation describing approach to equilibrium via opposing firstorder reactions for the change of visible absorbance $(\Delta A)$ of SP dye-containing samples, i.e., in the present cases, is given by $\Delta A / \Delta t=\mathrm{k}_{\mathrm{f}}\left(A_{0}-A_{\mathrm{t}}\right)-\mathrm{k}_{\mathrm{r}}\left(A_{\mathrm{t}}\right)$, where $\Delta A / \Delta t=$

TABLE I. Unit cell parameter and dynamic behavior of photochromism of SP dye in nonporous, hexagonal mesoporous, and fluorinated mesoporous materials.

\begin{tabular}{|c|c|c|c|c|}
\hline \multirow[b]{2}{*}{ Material } & \multicolumn{2}{|c|}{ Unit cell parameter (nm) } & \multirow{2}{*}{$\begin{array}{c}\text { Band } \\
\text { maximum } \\
\text { position } \\
(\mathrm{nm})\end{array}$} & \multirow[b]{2}{*}{$\Delta A$} \\
\hline & $\begin{array}{c}\text { As- } \\
\text { synthesized }\end{array}$ & Calcined & & \\
\hline Nonporous & $\ldots$ & $\ldots$ & 515 & 0.0219 \\
\hline Hexagonal mesoporous & 4.03 & 2.93 & 550 & 0.0943 \\
\hline Fluorinated mesoporous & 4.86 & 4.17 & 553 & 0.2244 \\
\hline
\end{tabular}


rate of change of visible absorbance $\left(\mathrm{s}^{-1}\right), \mathrm{k}_{\mathrm{f}}=$ firstorder coloration rate constant $\left(\mathrm{s}^{-1}\right), \mathrm{k}_{\mathrm{r}}=$ first-order decoloration rate constant $\left(\mathrm{s}^{-1}\right), A_{0}=$ visible absorbance if all SP existed in the colored form, and $A_{\mathrm{t}}=$ visible absorbance at any time $t^{20}$

Photochemical and photophysical studies offer a wide variety of probes that show selective high sensitivity to environmental parameters such as polarity, viscosity, porosity, and local geometry. ${ }^{23}$ Hexagonal mesoporous materials $(\Delta A=0.0943)$ show higher dynamic photochromism than non-porous materials $(\Delta A=0.0219)$. Although two materials have similar composition, the differences in the results arise from the lack of aggregation of the SP dye in the well-ordered hexagonal mesoporous structure. On the other hand, fluorinated mesoporous materials $(\Delta A=0.2244)$ have higher photochromism than hexagonal mesoporous materials $(\Delta A=$ 0.0943). Although the two materials have similar porosities, this results from more effective immobilization of the dye molecule in the fluorinated mesoporous materials. Hydrophobic organic functional groups (SP dyes) can be more easily incorporated in fluorinated mesoporous materials than in pure mesoporous materials because fluorinated mesoporous organosilicate materials have the electronegative $\mathrm{F}$ sites in the framework.

For all applications of organic photochromic dyes, a suitable matrix is indispensable. To overcome the aggregation and improve the stability of the dyes, the used films in this study through calcination process are preferred than mesophase films without calcination process. Starting from a mixture of organically modified silanes, however, it was possible to develop a system with enough flexibility to ensure good photochromic activity. It was also found that some additives e.g., $1 \mathrm{H}, 1 \mathrm{H}, 2 \mathrm{H}$, $2 \mathrm{H}$-perfluoroalkyltrimethoxysilane improved the photostability of the dye. ${ }^{24}$ Table I shows that $\Delta A$ can be enhanced by about 0.2244 by incorporating perfluoroalkyl chains. This is probably due to the hydrophobic environment created by perfluoroalkyl chains surrounding the dye molecules.

Usually nonporous silica films with incorporated SP dye show shorter wavelength region $(515 \mathrm{~nm})$ because of the aggregation of the SP dye. Mesoporous silica films with incorporated SP dye show longer wavelength region $(550 \mathrm{~nm})$. These results arise from the lack of aggregation of the SP dye and steric factors (porosity) at the photostationary state after UV irradiation. Fluorinated mesoporous films with interaction between SP dye and fluorine show also longer wavelength region $(553 \mathrm{~nm})$. These results arise from the lack of aggregation of the SP dye and hydrophobic interaction at the photostationary state after UV irradiation. The absorption peaks of the fluorinated mesoporous films with the SP dye shifted to longer wavelength compared to the non-porous and the hexagonal mesoporous materials. The above results were normalized taking into account the thickness of film for each sample. The photochromism efficiency of SP dyes increases in the order nonporous silica < hexagonal mesoporous silica $<$ fluorinated mesoporous organosilicate films.

\section{CONCLUSIONS}

In summary, we have shown that fluorinated mesoporous organosilicate films have been synthesized by sol-gel spin-coating on a quartz substrate using 17FDTMS, TMOS, and CTACl as the fluoro-precursor, silica source, and supramolecular template, respectively. The relatively high efficiency of the photochromism of $\mathrm{SP}$ in fluorinated mesoporous organosilicate films is due to the hydrophobic environment created by perfluoroalkyl chains surrounding the dye molecules and the enhancement in matrix flexibility by the long perfluoroalkyl chains. This suggests that such films are promising materials for applications such as optical shutters and light modulators. In future work, physical dynamic photochromism will be studied through lifetime and decay phenomena at room temperature.

\section{ACKNOWLEDGMENTS}

This work was supported by Grant No. R01-2003-00010125-0 from the Basic Research Program of the Korea Science \& Engineering Foundation and the Brain Korea 21 project. The authors acknowledge Dr. Jae Hong Kim (Kyung Hee University) for synthesis of spiropyran.

\section{REFERENCES}

1. C.T. Kresge, M.E. Leonowicz, W.J. Roth, J.C. Vartuli, and J.S. Beck: Ordered mesoporous molecular sieves synthesized by a liquid-crystal template mechanism. Nature 359, 710 (1992).

2. J.Y. Ying, C.P. Mehnert, and M.S. Wong: Synthesis and applications of supramolecular-templated mesoporous materials. Angew. Chem. Int. Ed. Engl. 38, 56 (1999).

3. U. Ciesla and F. Schüth: Ordered mesoporous materials. Microporous. Mesoporous. Mater. 27, 131 (1999).

4. C.M. Yang and K.J. Chao: Functionalization of molecularly templated mesoporous silica. J. Chin. Chem. Soc. 49, 883 (2002).

5. M. Ogawa: Formation of novel oriented transparent films of layered silica-surfactant nanocomposites. J. Am. Chem. Soc. 116, 7941 (1994).

6. Y. Lu, R. Ganguli, C.A. Drewien, M.T. Anderson, C.J. Brinker, W. Gong, Y. Guo, H. Soyez, B. Dunn, M.H. Huang, and J.I. Zink: Continuous formation of supported cubic hexagonal mesoporous films by sol-gel dip-coating. Nature 389, 364 (1997).

7. C.J. Brinker, Y. Lu, A. Sellinger, and H. Fan: Evaporationinduced self-assembly: nanostructures made easy. Adv. Mater. 11, 579 (1999).

8. M. Ogawa and N. Masukawa: Preparation of transparent thin films of lamellar, hexagonal and cubic silica-surfactant mesostructured materials by rapid solvent evaporation methods. Microporous. Mesoporous. Mater. 38, 35 (2000). 
9. J.Y. Bae, J.I. Jung, O.H. Park, B.S. Bae, K.T. Ranjit, and L. Kevan: Synthesis and characterization of mesoporous silica films by spin-coating on silicon: Photoionization of methylphenothiazine and photoluminescence of erbium 8-hydroxyquinolinate in mesoporous silica films. Stud. Surf. Sci. Catal. 146, 65 (2003).

10. B. Lebeau, C. Marichal, A. Mirjol, G.J. de A.A. Soler-Illia, R. Buestrich, M. Popall, L. Mazerolles, and C. Sanchez: Synthesis of highly ordered mesoporous hybrid silica from aromatic fluorinated organosilane precursors. New J. Chem. 27, 166 (2003).

11. A. Stein, B.J. Melde, and R.C. Schroden: Hybrid inorganicorganic mesoporous silicates-nanoscopic reactors coming of age. Adv. Mater. 12, 1403 (2000).

12. A. Sayari and S. Hamoudi: Periodic mesoporous silica-based organic-inorganic nanocomposite materials. Chem. Mater. 13, 3151 (2001).

13. M. Orenstein, J. Katriel, and S. Speiser: Optical bistability in molecular systems exhibiting nonlinear absorption. Phys. Rev. A 35, 2175 (1987).

14. I.R. Matias, M. Lopez-Amo, G. Fiksman, J.M. Oton, D. Levy, and F. Del Monte: Dynamic behavior of sol-gel gel-glass based thermochromic material applied toward development of practical optical temperature sensors. Opt. Eng. 37, 2620 (1998).

15. G. Wirnsberger, B.J. Scott, B.F. Chmelka, and G.D. Stucky: Fast response photochromic mesostructures. Adv. Mater. 12, 1450 (2000).

16. J.C. Cran and R.J. Guglielmetti: Organic Photochromic and Thermochromic Compounds (Plenum Press, New York and London, 1999), p. 11.
17. S. Oliver, A. Kuperman, N. Coombs, A. Louth, and G.A. Ozin: Lamellar aluminophosphates that mimic radiolaria and diatom skeletons. Nature 378, 47 (1995).

18. R.M. Silverstein, G.C. Bassler, and T.C. Morrill, Spectrometric Identification of Organic Compounds (John Wiley \& Sons Press, New York, 1991), p. 130.

19. S.J. Clarson and J.A. Semyen: Siloxane Polymers (PTR Prentice Hall, Eaglewood Cliffs, NJ, 1933), p. 327.

20. J.B. Flannery, Jr.: The photo- and thermochromic transients from substituted 1',3',3'-trimethylindolinobenzospiropyrans. J. Am. Chem. Soc. 90, 5660 (1968).

21. O.H. Park, S.Y. Seo, J.I. Jung, J.Y. Bae, and B.S. Bae: Photoluminescence of mesoporous silica films impregnated with an erbium complex. J. Mater. Res. 18, 1039 (2003).

22. J.Y. Bae, O.H. Park, J.I. Jung, K.T. Ranjit, and B.S. Bae: Photoionization of methylphenothiazine and photoluminescence of erbium 8-hydroxyquinolinate in transparent mesoporous silica films by spin-coating on silicon. Microporous. Mesoporous. Mater. 67, 265 (2004).

23. D. Levy and D. Avnir: Effects of the changes in the properties of silica cage along the gel/xerogel transition on the photochromic behavior of trapped spiropyrans. J. Phys. Chem. 92, 4734 (1988).

24. L. Hou, B. Hoffman, H. Schmidt, and M. Menning: Effect on heat treatment and additives on the photochromic and mechanical properties of sol-gel derived photochromic coatings containing spirooxazine. J. Sol-Gel Sci. Technol. 8, 923 (1997). 